\title{
High-yield production of 1,3-propanediol from glycerol by metabolically engineered Klebsiella pneumoniae
}

Jung Hun Lee ${ }^{1 \dagger}$, Moo-Young Jung ${ }^{2 \dagger}$ and Min-Kyu Oh ${ }^{1^{*}}$

\begin{abstract}
Background: Glycerol is a major byproduct of the biodiesel industry and can be converted to 1,3-propanediol (1,3-PDO) by microorganisms through a two-step enzymatic reaction. The production of 1,3-PDO from glycerol using microorganisms is accompanied by formation of unwanted byproducts, including lactate and 2,3-butanediol, resulting in a low-conversion yield.
\end{abstract}

Results: Klebsiella pneumoniae was metabolically engineered to produce high-molar yield of 1,3-PDO from glycerol. First, the pathway genes for byproduct formation were deleted in K. pneumoniae. Then, glycerol assimilation pathways were eliminated and mannitol was co-fed to the medium. Finally, transcriptional regulation of the dha operon were genetically modified for enhancing 1,3-propanediol production. The batch fermentation of the engineered strain with co-feeding of a small amount of mannitol yielded $0.76 \mathrm{~mol}$ 1,3-PDO from $1 \mathrm{~mol}$ glycerol.

Conclusions: Klebsiella pneumoniae is useful microorganism for producing 1,3-PDO from glycerol. Implemented engineering in this study successfully improved 1,3-PDO production yield, which is significantly higher than those reported in previous studies.

Keywords: 1, 3-PDO, Klebsiella pneumoniae, Glycerol, Byproducts, Glycerol assimilation pathway, Co-substrate, Mannitol, dha operon

\section{Background}

Biodiesel production has increased significantly over the past decade and, along with it, the production of glycerol, a byproduct of biodiesel production, has also increased. Intensive studies have been performed for adding value on glycerol [1]. Glycerol can be converted into a number of valuable products, including 1,3-propanediol (1,3PDO), 3-hydroxypropionic acid, 2,3-butanediol (2,3$\mathrm{BDO})$, and lactate by metabolic engineering [2]. Among these, 1,3-PDO is a valuable chemical product that can be used as a solvent in the cosmetic industry and as a monomer to synthesize biopolymers. In 2012, the international demand for 1,3-PDO was $60.2 \mathrm{kton}$, and this has

\footnotetext{
*Correspondence: mkoh@korea.ac.kr

†Jung Hun Lee and Moo-Young Jung contributed equally to this work ${ }^{1}$ Department of Chemical and Biological Engineering, Korea University, Seongbuk-gu, Seoul 02841, Republic of Korea

Full list of author information is available at the end of the article
}

been expected to grow by $150 \%$ until 2019 [3]. Among the chemical and biochemical processes for 1,3-PDO production, fermentation has several advantages over chemical processes, including a requirement for moderate reaction conditions $[4,5]$.

Certain microorganisms, including Klebsiella, Citrobacter, Enterobacter, Bacillus, Lactobacillus, and Clostridium, are natural 1,3-PDO producers and have genes that encode enzymes for the required reactions on their chromosomes. Among the natural producers, Klebsiella pneumoniae in particular has advantages. This species grows fast on glycerol under both aerobic and anaerobic conditions, and a number of genetic modification tools have been already established. In addition, $K$. pneumoniae produces vitamin $\mathrm{B}_{12}$, a coenzyme of glycerol dehydratase, which is involved in synthesis of the 1,3-PDO precursor, 3-hydroxypropionaldehyde [6]. For these reasons, $K$. pneumoniae has often been used as a 
host for the biochemical production of 1,3-PDO from glycerol. 1,3-PDO production has been increased by various strategies such as preventing byproduct formation, co-producing valuable metabolites, and rebalancing reducing cofactors [7-10]. The titers, productivities, and yields of 1,3-PDO from glycerol achieved in recent studies are summarized in Table 1. When producing 1,3-PDO using microorganisms, many unwanted byproducts, such as lactate and 2,3-BDO, are produced. In particular, the separation of 1,3-PDO from 2,3-BDO significantly increases the overall cost of the process [11]. Therefore, generating a higher molar yield of 1,3-PDO from glycerol is highly desirable [7].

In this present study, we utilized several strategies to generate a higher molar yield of 1,3-PDO from glycerol (Fig. 1). First, genes in the pathway responsible for production of unwanted byproducts were eliminated, including genes encoding lactate dehydrogenase (ldhA, Gene ID: 12545375 [Genbank]), formate acetyltransferase ( $p f l B$, Gene ID: 12544797 [Genbank]), and alphaacetonelactate decarboxylase (budA, Gene ID: 12546009 [Genbank]) [12, 13]. Second, glycerol assimilation pathways were eliminated by deleting the genes encoding glycerol kinase ( $g l p K$, Gene ID: 12548005 [Genbank]) and glycerol dehydrogenase (dhaD, Gene ID: 12547488 [Genbank]) (Fig. 1a). The resulting strain had an improved 1,3-PDO molar yield from glycerol when a co-substrate, mannitol, was supplied for cell growth and maintenance. Finally, dha regulators were engineered for more efficient conversion of glycerol to 1,3-PDO (Fig. 1b). Negative regulators of DhaK (NCBI-Protein ID: AEJ99992) and DhaM (NCBI-Protein ID: AEJ99994) were deleted, while a positive regulator, DhaL (NCBI-Protein ID: AEJ99993), was overexpressed [14]. The resulting strain produced 1,3-PDO more rapidly during batch fermentation with a molar yield of $0.76 \mathrm{~mol} \mathrm{~mol}^{-1}$ glycerol. This yield was superior to those reported in other studies, which have reported molar yields of up to $0.66 \mathrm{~mol} \mathrm{~mol}^{-1}$ glycerol (Table 1) $[10,15,16]$.

\section{Methods}

\section{Strains, plasmids, and primers}

The strains, plasmids, and primers used in this study are listed in Table 2 and Additional file 1: Table S1. All K. pneumoniae strains were derived from the wild-type strain KCTC 2242 (Korean Collection for Type Culture) [17]. KMK-01, KMK-02, and KMK-05 strains have been reported in our previous study [12]. To construct additional deletion mutants, $\lambda$ red recombination was used with pRedET-transformed strains [18]. The plasmid pKD4 was used to synthesize an antibiotic-resistant gene flanked by FLP recognition target sites, while 707-FLP was used to eliminate the resistance cassette. The KMK11, KMK-12, KMK-21, KMK-22, KMK-23, and KMK-46 strains (Table 2) were constructed using this method. Deletions of target genes were confirmed by agarose gel electrophoresis (Additional file 2: Figure S1) and sequencing their PCR products generated with genomic DNA of the strains and confirmation primers, indicated by 'con' in their name in Additional file 1: Table S1.

Table 1 Comparison of the recent studies for 1,3-propanediol production from glycerol using engineered Klebsiella pneumonia

\begin{tabular}{|c|c|c|c|c|c|}
\hline Sources & $\begin{array}{l}\text { Fermentation } \\
\text { Time (h) }\end{array}$ & Titer $\left(\mathrm{g} \mathrm{L}^{-1}\right)$ & $\begin{array}{l}\text { Yield (mol mol } \\
\text { glycerol) }\end{array}$ & $\begin{array}{l}\text { Productivity } \\
\left(g^{-1} h^{-1}\right)\end{array}$ & Comments \\
\hline Lin et al. [10] & 30 & 76.80 & 0.66 & 2.56 & Fed-batch \\
\hline Kumar et al. [9] & 36 & 38.95 & 0.49 & 1.08 & Fed-batch with no BDO production \\
\hline Wang et al. [7] & 33 & 86.00 & 0.59 & 2.69 & Fed-batch \\
\hline Xin et al. [8] & 30 & 76.20 & 0.43 & 2.54 & Fed-batch \\
\hline This study & 24 & 20.59 & 0.76 & 0.86 & Batch with no BDO production \\
\hline
\end{tabular}

(See figure on next page.)

Fig. 1 Engineered metabolic pathways and regulators in this study. a Metabolic pathways of K. pneumoniae for 1,3-propanediol (1,3-PDO) production and microbial growth. Eliminated pathways in this study on byproducts formation and glycerol assimilation are presented with dashed gray arrows. Pathways with multiple steps are presented with dotted arrows. The acronyms, 3-HPA, DHA, G3P, DHAP, and TCA, refer to 3-hydroxypropionaldehyde, dihydroxyacetone, glyceraldehyde 3-phosphate, dihydroxyacetone phosphate, and tricarboxylic acid, respectively. Genes involved in those pathways are in italics. $\mathbf{b}$ Engineering scheme of dha operon with its regulations. PdhaK, the promoter of dhaK, is transcriptionally repressed by DhaK and DhaM and activated by DhaL. ADP forms a complex with DhaL, which binds to the sensing domain of DhaR, thus activating DhaR. ADP and DhaL complexes are inactivated by DhaM-mediated phosphorylation. DhaK inactivates DhaR by binding Activated DhaR by ADP-DhaL complex activates dhaT expression, while represses dhaB. Black solid arrows stand for activation and gray closed arrows stand for inhibition. Black dashed arrows indicate protein modification [14]. KMK-23M, KMK-46, and KMY on the right-hand side represent the engineered strains (Table 2) 
a

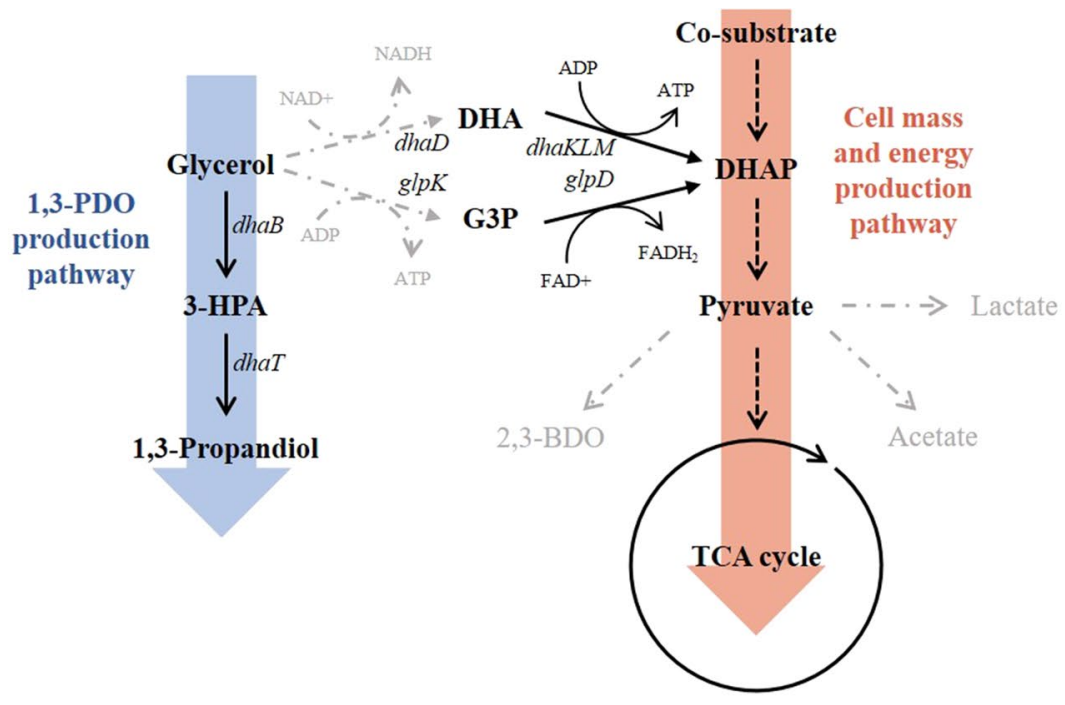

b
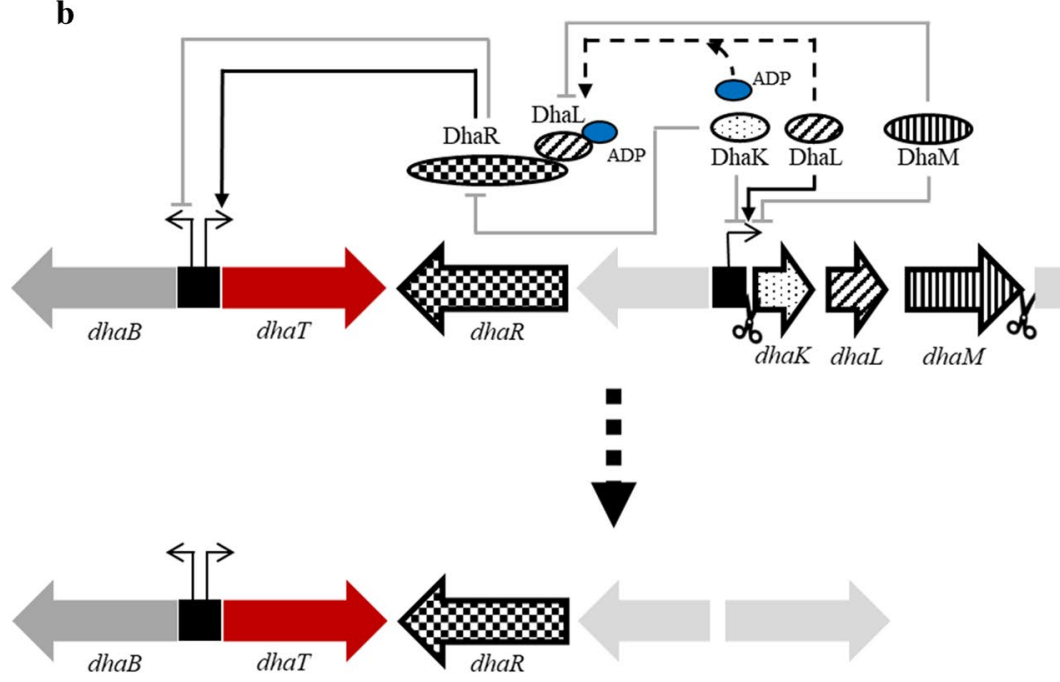

KMK-46

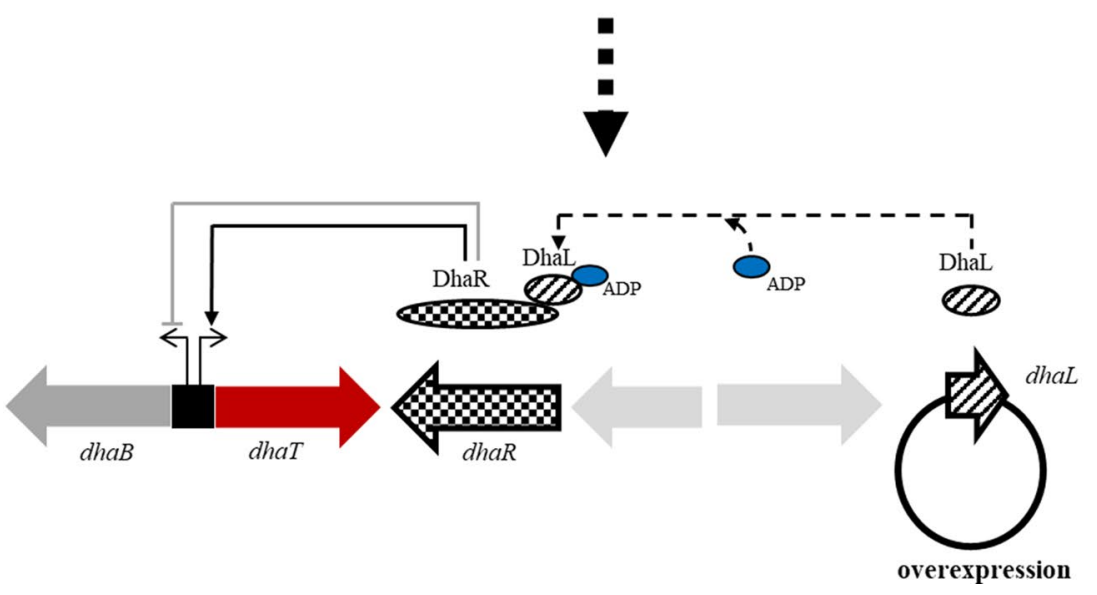

KMY 
Table 2 K. pneumoniae strains and plasmids used in this study

\begin{tabular}{|c|c|c|}
\hline Strain or plasmid & Description & Source \\
\hline \multicolumn{3}{|l|}{ Strains } \\
\hline KMK-01 & KCTC $2242 \triangle w a b G$ & {$[12]$} \\
\hline KMK-02 & KCTC $2242 \triangle w a b G \Delta l d h A$ & {$[12]$} \\
\hline KMK-05 & KCTC $2242 \triangle w a b G \triangle 1 d h A \triangle p f l B$ & {$[12]$} \\
\hline KMK-12 & KCTC $2242 \triangle w a b G \triangle l d h A \triangle p f l B \triangle b u d A$ & This study \\
\hline KMK-21 & KCTC $2242 \triangle w a b G \Delta l d h A \triangle p f l B \triangle b u d A \triangle d h a D$ & This study \\
\hline KMK-22 & KCTC $2242 \triangle w a b G \Delta l d h A \triangle p f l B \Delta b u d A \triangle g l p K$ & This study \\
\hline KMK-23 & KCTC $2242 \Delta w a b G \Delta / d h A \triangle p f l B \triangle b u d A \Delta d h a D \Delta g l p K$ & This study \\
\hline KMK-23M & KMK-23 edited 5'-UTR of mt/A for reduced expression level & This study \\
\hline KMK-46 & KMK-23M $\triangle$ dhaKLM & This study \\
\hline KMY & KMK-46 harboring pZS21 dhaL & This study \\
\hline \multicolumn{3}{|l|}{ Plasmids } \\
\hline pRedET & $\lambda$ phage red $\gamma, \beta, a$-producing vector, pBAD_promoter; ori101 Tet ${ }^{r}$ & Gene bridges \\
\hline 707-FLP & Flp recombinase-producing vector; Psc101 ori cl1578 Tetr & Gene bridges \\
\hline pKD4 & FRT-flanked resistance cassette-involved vector; oriRy $\mathrm{Km}^{r}$ & {$[16]$} \\
\hline pZA31::MCS & Expression vector, $\mathrm{Cm}^{\mathrm{R}}$, p15A ori & Expressys \\
\hline pZS21::MCS & Expression vector, $\mathrm{Km}^{\mathrm{R}}, \mathrm{pSC} 101$ ori & Expressys \\
\hline pZA-Cas9 & pZA31MCS, but $P_{\text {Lteto-1:.:Cas9-PsacB:.:sacB }}$ & {$[23]$} \\
\hline pZS-CRISPR & pZS21MCS, but $P_{\text {LtetO-1 } 1: \text { TracerRNA-PsacB::sacB }}$ & {$[23]$} \\
\hline pZS-CRISPR mtIA & pZS21MCS, but $P_{\text {Lteto-1 }}:$ TracerRNA-5'UTR(mt/A)-PsacB::SacB & This study \\
\hline pZS21dhaL & pZS21::MCS harboring dhaL from wild-type K. pneumoniae & This study \\
\hline pZA31budABC & pZA31::MCS harboring budABC from wild-type K. pneumoniae & This study \\
\hline
\end{tabular}

$A p^{R}$ ampicillin, Tet $^{R}$ tetracycline, $\mathrm{Cm}^{R}$ chloramphenicol, $\mathrm{Km}^{R}$ kanamycin resistance

Decreased $m t l A$ (Gene ID: 12547935 [Genbank]) gene expression in KMK-23 was achieved by mutation of its $5^{\prime}$-untranslated region (UTR). The sequence of $5^{\prime}$-UTR of $m t l A$ has been designed by RBS calculator $[19,20]$ to have $62 \%$ mtlA expression compared to the parental strain. The sequence 5'-TAGACAGAGTCTAAC AGACCATCGAGGAACGTATG- 3 ', which consists of bases -32 to -1 from the $m t l A$ translation start codon, was chosen and introduced to the $5^{\prime}$-UTR region using genome editing with CRISPR/Cas9 [21, 22]. The plasmids, pZA-Cas9 and pZS-CRISPR, for genome editing were used as reported in a previous study [23]. The DNA fragments, mtlA CRISPR F and R (Additional file 1: Table S1), were synthesized, annealed, and inserted into pZS-CRISPR at BsaI to generate crRNA. The resulting plasmid was designated pZS-CRISPR mtlA. The DNA fragments, and mtlA rescue $\mathrm{F}$ and $\mathrm{R}$ (Additional file 1 : Table S1) were synthesized, annealed, and used as rescue DNA. The plasmid pZS-CRISPR $m t l A$ and rescue DNA were transformed into a pZA-Cas9 containing KMK-23 strain. The genome-edited strain, KMK-23M, was confirmed by DNA sequencing.

The dhaL gene was cloned into the pZS21MCS plasmid using the Gibson assembly method $[24,25]$. The plasmid pZS21::MCS was cut using restriction enzymes, HindIII and $M l u \mathrm{I}$, and assembled with amplified dhaL gene fragment generated with primers dhaL $\mathrm{F}$ and $\mathrm{R}$ (Additional file 1: Table S1) by NEBuilder Assembly Tool (http:// nebuilder.neb.com). The resulting plasmid, pZS21dhaL, was transformed into KMK-46 to construct KMY. The engineered strains and plasmids were confirmed by DNA sequencing.

\section{Media and culture conditions}

In this study, the media components used in addition to the carbon sources were as follows: $3 \mathrm{~g} \mathrm{~L}^{-1} \mathrm{KH}_{2} \mathrm{PO}_{4}$, $6.8 \mathrm{~g} \mathrm{~L}^{-1} \mathrm{Na}_{2} \mathrm{HPO}_{4}, 0.75 \mathrm{~g} \mathrm{~L}^{-1} \mathrm{KCl}, 5.35 \mathrm{~g} \mathrm{~L}^{-1}\left(\mathrm{NH}_{4}\right)_{2} \mathrm{SO}_{4}$, $0.28 \mathrm{~g} \mathrm{~L}^{-1} \mathrm{Na}_{2} \mathrm{SO}_{4}, 0.26 \mathrm{~g} \mathrm{~L}^{-1} \mathrm{MgSO}_{4} \cdot 7 \mathrm{H}_{2} \mathrm{O}, 0.42 \mathrm{~g} \mathrm{~L}^{-1}$ citric acid, $10 \mathrm{~g} \mathrm{~L}^{-1}$ yeast extract, $10 \mathrm{~g} \mathrm{~L}^{-1}$ casamino acids, $1 \mathrm{~mL}$ of a microelement solution $\left(0.07 \mathrm{~g} \mathrm{~L}^{-1}\right.$ $\mathrm{ZnCl}_{2}, 0.1 \mathrm{~g} \mathrm{~L}^{-1} \mathrm{Na}_{2} \mathrm{MO}_{4} \cdot 2 \mathrm{H}_{2} \mathrm{O}, 0.1 \mathrm{~g} \mathrm{~L}^{-1} \mathrm{MnCl}_{2} \cdot 4 \mathrm{H}_{2} \mathrm{O}$, $0.2 \mathrm{~g} \mathrm{~L}^{-1} \mathrm{CoCl}_{2} \cdot 6 \mathrm{H}_{2} \mathrm{O}, 0.025 \mathrm{~g} \mathrm{~L}^{-1} \mathrm{NiCl}_{2} \cdot 7 \mathrm{H}_{2} \mathrm{O}, 0.02 \mathrm{~g} \mathrm{~L}^{-1}$ $\mathrm{CuCl}_{2} \cdot 2 \mathrm{H}_{2} \mathrm{O}$, and $\left.0.06 \mathrm{~g} \mathrm{~L}^{-1} \mathrm{H}_{3} \mathrm{BO}_{3}\right)$, and $1 \mathrm{~mL}$ of an iron solution $\left(10 \mathrm{~g} \mathrm{~L}^{-1} \mathrm{FeSO}_{4} \cdot 7 \mathrm{H}_{2} \mathrm{O}\right)$. Strains were selected on $\mathrm{LB}$ medium $\left(10 \mathrm{~g} \mathrm{~L}^{-1}\right.$ tryptone, $5 \mathrm{~g} \mathrm{~L}^{-1}$ yeast extract, and $10 \mathrm{~g} \mathrm{~L}^{-1} \mathrm{NaCl}$ ) supplemented with the appropriate antibiotics, such as $50 \mu \mathrm{g} \mathrm{mL}^{-1}$ chloramphenicol, $100 \mu \mathrm{g} \mathrm{mL}^{-1}$ kanamycin, and $20 \mu \mathrm{g} \mathrm{mL}^{-1}$ tetracycline.

To evaluate byproducts production of KMK-01, KMK02, KMK-05, KMK-11, and KMK-12, $55 \mathrm{~g} \mathrm{~L}^{-1}$ glycerol 
was fed as a carbon source. For the strains, which the glycerol assimilation pathway was eliminated, $40 \mathrm{~g} \mathrm{~L}^{-1}$ glycerol was fed as a carbon source along with $20 \mathrm{~g} \mathrm{~L}^{-1}$ of mannitol, glucose, xylose, or galactose. For the KMY strain, the medium was supplemented with kanamycin $\left(100 \mu \mathrm{g} \mathrm{mL}^{-1}\right)$. Cultures were incubated in $30 \mathrm{~mL}$ volumes from $1 \%(\mathrm{v} / \mathrm{v})$ inoculums in 100-mL Erlenmeyer flasks sealed with silicon stoppers under microaerobic conditions at $37{ }^{\circ} \mathrm{C}$ with shaking at $250 \mathrm{rpm}$. Batch fermentation was performed in a volume of $1 \mathrm{~L}$ from $5 \%$ $(\mathrm{v} / \mathrm{v})$ inoculums in a $2.5 \mathrm{~L}$ bioreactor (Bio Control \& System, Daejeon, South Korea). The conditions for batch fermentation were $37^{\circ} \mathrm{C}$, shaking at $150 \mathrm{rpm}, 0.4 \mathrm{vvm}$, and $\mathrm{pH}$ maintained between 6.5 and 7.0, where the $\mathrm{pH}$ was adjusted with $5 \mathrm{M} \mathrm{NaOH}$ and antifoam 204 (Sigma, St. Louis, MO, USA) was added as needed. Dissolved oxygen was monitored by D500 OxyProbe ${ }^{\circledR}$ II DO Sensor (Broadley-James Corporation, Irvine, CA, USA) during the fermentation. The cultivations were performed at least three times.

\section{Analytical methods}

The cell density was monitored by UV visibility spectrophotometer (Shimazu UV mini 1240; Shimadzu, Tokyo, Japan) at $600 \mathrm{~nm}\left(\mathrm{OD}_{600}\right)$. Culture broth $(1 \mathrm{~mL})$ was transferred to microcentrifuge tubes and centrifuged at $13,000 \mathrm{rpm}$ for $10 \mathrm{~min}$ at $4{ }^{\circ} \mathrm{C}$. Supernatants were transferred to new microcentrifuge tubes and used for analysis of metabolites. To measure concentrations of 1,3-PDO, 2,3-BDO, acetate, lactate, succinate, glycerol, mannitol, glucose, xylose, and galactose, high-performance liquid chromatography (Younglin Instrument ACME9000, Seoul, South Korea) with a Sugar SH1011 column
(Shodex, Tokyo, Japan) maintained at $70{ }^{\circ} \mathrm{C}$, an RI detector maintained at $45^{\circ} \mathrm{C}$, and $5 \mathrm{mM} \mathrm{H}_{2} \mathrm{SO}_{4}$ as the mobile phase with a flow rate of $0.6 \mathrm{~mL} \mathrm{~min}^{-1}$ was used. NADH and $\mathrm{NAD}^{+}$assay was conducted by NAD/NADH-GloTM Assay G9071 (Promega, Madison, WI, USA) according to the manufacturer's protocol. Each strain for the assay was cultured to the mid-log phase $\left(\mathrm{OD}_{600}=1\right)$ with $30 \mathrm{~mL}$ working volume in $100-\mathrm{mL}$ Erlenmeyer flask and harvested for the assay.

\section{Real-time RT-PCR}

The strains were cultured in flask and harvested in early exponential phase $(\mathrm{OD} \sim 1)$. RNA was prepared by RNeasy Mini Kit (Qiagen, Hilden, Germany) according to the manufacturer's protocol. Complementary DNA was synthesized by PrimeScript ${ }^{\mathrm{TM}}$ Reverse Transcriptase 2680A (Takara, Shiga, Japan). For PCR, QPCR Green Master Mix (LRox, biotechrabbit, Hennigsdorf, Germany) was used according to manufacturer's protocol. Relative gene expression levels were measured by quantitative PCR by StepOne $^{\mathrm{TM}}$ Real-Time PCR System (Applied Biosystems, Foster City, CA, USA).

\section{Results and discussion}

Pathway engineering to reduce byproduct formation

For removing pathogenicity of the strain, we deleted wabG gene from K. pneumoniae KCTC 2242, which is responsible for making a lipopolysaccharide [26]. The resulting strain, KMK-01 is a parental strain in this study. K. pneumoniae KMK-01 produces $1,3-\mathrm{PDO}$ as a major product from glycerol. At the same time, it also produces a significant number of byproducts, including 2,3-BDO, lactate, acetate, and succinate (Table 3). Deletions of

Table $3 \mathrm{OD}_{600}$, glycerol consumption and metabolite production yields in $K$. pneumoniae wild type and engineered strains after $24 \mathrm{~h}$ of flask culture ${ }^{\mathrm{a}}$

\begin{tabular}{|c|c|c|c|c|}
\hline \multicolumn{2}{|l|}{ IdhA } & \multirow[t]{2}{*}{$\Delta$} & \multirow{3}{*}{$\begin{array}{l}\Delta \\
\Delta\end{array}$} & \multirow{3}{*}{$\begin{array}{l}\Delta \\
\Delta \\
\Delta\end{array}$} \\
\hline$p f l B$ & & & & \\
\hline budA & & & & \\
\hline Strain name & KMK-01 & KMK-02 & KMK-05 & KMK-12 \\
\hline $\mathrm{OD}_{600}$ & 9.66 & 12.18 & 6.47 & 3.65 \\
\hline Consumed glycerol $\left(\mathrm{g} \mathrm{L}^{-1}\right)$ & 48.31 & 54.45 & 52.55 & 16.13 \\
\hline Acetate production $\left(\mathrm{g} \mathrm{L}^{-1}\right)$ & 1.42 & 1.51 & 0.00 & 1.34 \\
\hline Succinate production $\left(\mathrm{g} \mathrm{L}^{-1}\right)$ & 0.87 & 0.84 & 0.82 & 0.36 \\
\hline Lactate production $\left(\mathrm{g} \mathrm{L}^{-1}\right)$ & 2.89 & 0.00 & 0.59 & 0.00 \\
\hline 2,3-BDO production $\left(\mathrm{g} \mathrm{L}^{-1}\right)$ & 6.00 & 6.65 & 11.57 & 0.60 \\
\hline 1,3-PDO production $\left(\mathrm{g} \mathrm{L}^{-1}\right)$ & 17.94 & 20.14 & 20.11 & 6.30 \\
\hline 1,3-PDO productivity $\left(\mathrm{g} \mathrm{L}^{-1} \mathrm{~h}^{-1}\right)$ & 0.75 & 0.84 & 0.84 & 0.26 \\
\hline 1,3-PDO yield $\left(\mathrm{mol} \mathrm{mol}^{-1}\right)^{\mathrm{b}}$ & 0.45 & 0.45 & 0.46 & 0.47 \\
\hline
\end{tabular}

a Experiments were repeated three times independently

b Yield was calculated as produced metabolite ( $\mathrm{mol}) /$ consumed glycerol (mol) 
ldh $A$ and $p f l B$ have been reported significantly reducing the amounts of these byproducts when glucose is fed as a carbon source [12]. When KMK-02, the KMK$01 \Delta l d h A$ mutant, was cultured in glycerol, lactate production was reduced from 0.06 to $0 \mathrm{~mol} \mathrm{~mol}^{-1}$. KMK-05, the KMK-02 $\triangle p f l B$ mutant, produced no acetate, similar to previous results observed for glucose [12]. 1,3-PDO production increased from 17.94 to $20.14 \mathrm{~g} \mathrm{~L}^{-1}$ and $20.11 \mathrm{~g} \mathrm{~L}^{-1}$ in KMK-02 and KMK-05, respectively, compared to the parental strain, while the molar yield from glycerol was almost the same. Meanwhile, 2,3-BDO production increased in these mutants. Therefore, budA encoding 2,3-butanediol dehydrogenase, was deleted from the KMK-05 strain and the resulting strain was designated KMK-12. KMK-12 produced less 2,3-BDO than the parental strain, 0.04 compared to $0.23 \mathrm{~mol} \mathrm{~mol}^{-1}$, respectively. Despite the reduction in byproduct formation by KMK-12, the molar yield of 1,3-PDO from glycerol, $0.47 \mathrm{~mol} \mathrm{~mol}^{-1}$ glycerol, did not notably change (Table 3). Meanwhile, deletion of budA caused significant decreases in glycerol consumption and biomass production, resulting in a reduction in 1,3-PDO titer, as previously reported [13].

\section{Elimination of glycerol assimilation pathways to improve 1,3-PDO yield}

To improve the molar yield of 1,3-PDO from glycerol, glycerol assimilation pathways were eliminated on $K$. pneumoniae. Two glycerol assimilation pathways, which start from glycerol and lead into glycolysis, exist in $K$. pneumoniae (Fig. 1a). Glycerol kinase (GlpK, NCBIProtein ID: AEK00501) is responsible for the conversion of glycerol to glycerol 3-phosphate, while glycerol dehydrogenase (DhaD, NCBI-Protein ID: AEJ99991) converts glycerol to dihydroxyacetone with NADH production [27-29]. GlpK is active under aerobic conditions, while DhaD is active under anaerobic conditions [29]. Strains KMK-21 and 22 were constructed by deleting dhaD and $g l p K$, respectively, from KMK-12. Strain KMK-23 was generated by deleting both $d h a D$ and glpK from KMK12. When these strains were cultured for $24 \mathrm{~h}$ in flasks containing glycerol, there were decreases in 1,3-PDO productions and molar yields in KMK-12 and KMK-23, while a marginal increase in 1,3-PDO production was in KMK-22 (Additional file 3: Table S2). It is because DhaDDhaKLM pathway provides $1 \mathrm{~mol}$ of NADH for 1,3PDO production, while GlpK-GlpD pathway does not (Fig. 1a). Therefore, dhaD deletion resulted in decreases in 1,3-PDO production, while $g l p K$ deletion did not. To prove this, $\mathrm{NADH} / \mathrm{NAD}^{+}$ratios were measured in KMK12, KMK-21, KMK-22, and KMK-23 strains. The results also supported that the strains with dhaD deletion,
KMK-21 and KMK-23 produced less NADH, resulting in low NADH/NAD ${ }^{+}$ratios (Fig. 2a and b).

To enhance 1,3-PDO yield, glycerol flux towards assimilation should be restricted further. Therefore, glucose was supplied as co-substrate to replace the glycolytic flux generated from glycerol assimilation. When glycerol and glucose were supplied together, the molar yield of 1,3PDO from glycerol in KMK-21 and KMK-23 significantly increased (Table 4). Since glucose was not converted to 1,3-PDO (Additional file 4: Table S3), the molar yield of 1,3-PDO was calculated based on glycerol consumed. Deletion of dhaD (strain KMK-21) improved molar yield from 0.56 to $0.77 \mathrm{~mol} \mathrm{~mol}^{-1}$ compared to the parental strain (KMK-12). When dhaD was deleted, glycerol consumption was restricted because DhaD is active under microaerobic conditions and, therefore, this mutant assimilated very little glycerol. Deletion of $g l p K($ KMK-22) improved 1,3-PDO production from 4.87 to $6.09 \mathrm{~g} \mathrm{~L}^{-1}$ compared to KMK-12, with a marginal improvement in yield. This may be because deletion of $g l p K$ enhances DhaD activity by more than twofold according to Ashok et al. [30]. However, it also enhances the flux into glycerol assimilation pathways, draining glycerol for energy and cell mass production. Therefore, no gain in 1,3-PDO molar yield from glycerol was observed for KMK-22. When both the $g l p K$ and $d h a D$ genes were deleted, the molar yield of 1,3-PDO from glycerol improved from 0.56 to $0.84 \mathrm{~mol} \mathrm{~mol}^{-1}$ glycerol, with an improvement in titer from 4.87 to $5.27 \mathrm{~g} \mathrm{~L}^{-1}$. This implies that elimination of glycerol assimilation enhanced carbon flux from glycerol towards 1,3-PDO production, while energy and cell mass production were supported by flux from carbon to glucose. Compared to the previously reported molar yield of 1,3-PDO from glycerol, $0.60 \mathrm{~mol} \mathrm{~mol}^{-1}$ glycerol, $[15,16]$, the molar yield obtained by KMK-23 was much higher, $0.84 \mathrm{~mol} \mathrm{~mol}^{-1}$ glycerol. Despite that, we observed increased acetate production from engineered strains. Acetate production could be reduced by keeping glycerol or glucose concentration low during fed-batch fermentation $[8,31]$.

\section{Selecting a co-substrate for KMK-23}

After eliminating glycerol assimilation pathways, cosubstrates, i.e., glucose alternatives, were screened for efficient 1,3-PDO production. Mannitol, glucose, galactose, and xylose were tested as co-substrates with glycerol (Fig. 3). Out of the four co-substrates tested, mannitol resulted in the highest 1,3-PDO production titer, $7.84 \mathrm{~g} \mathrm{~L}^{-1}$, which is $48.7 \%$ more than that of glucose (Fig. 3). Comparing to the other three co-substrates, mannitol utilization pathway produces additionally $1 \mathrm{~mol}$ of NADH when mannitol-1-phosphate converts to fructose-6-phosphate $[32,33]$. Indeed, $\mathrm{NADH} / \mathrm{NAD}^{+}$ratio 

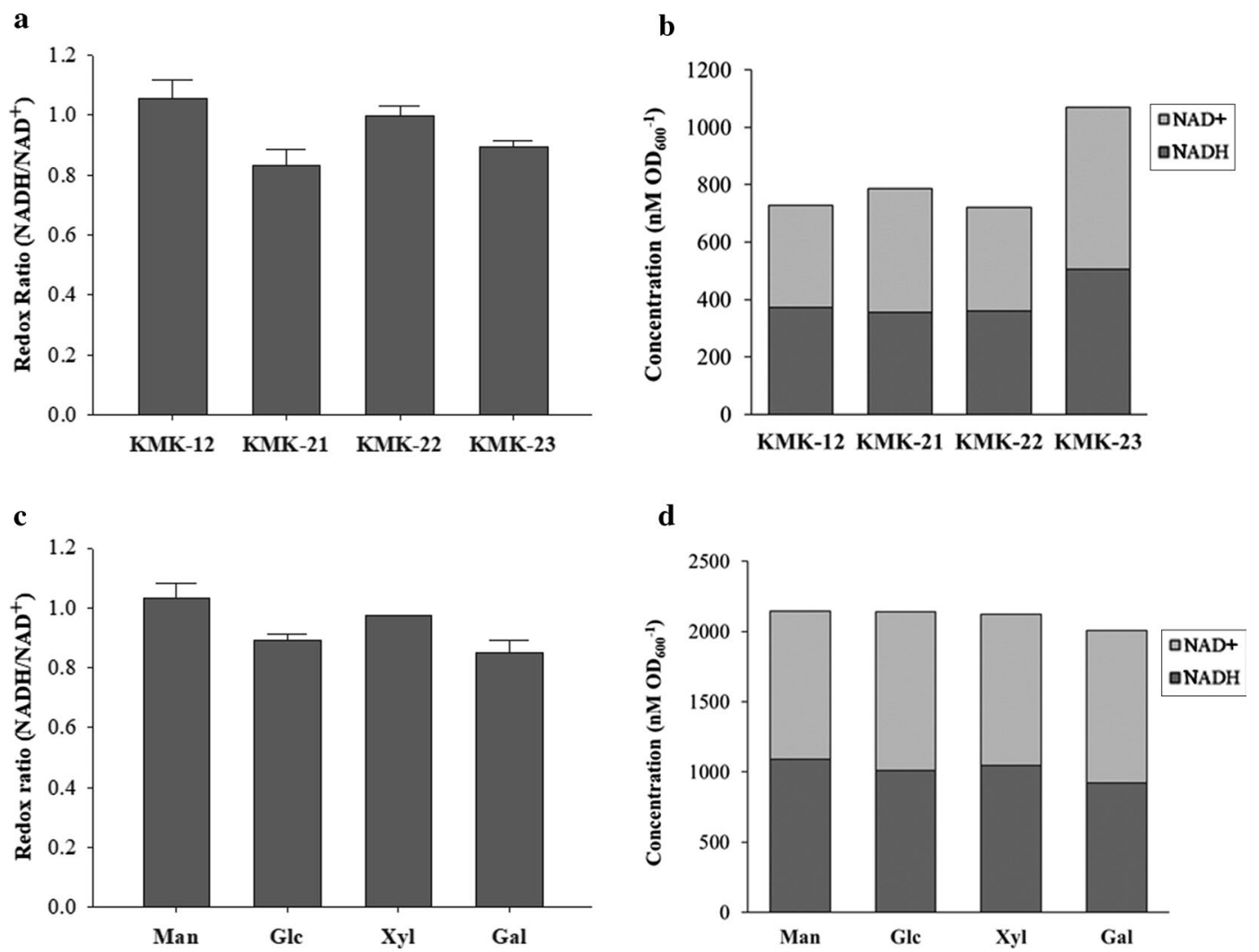

Fig. 2 a NADH/NAD ${ }^{+}$ratios and $\mathbf{b} N A D H$ and NAD ${ }^{+}$concentrations of KMK-12, KMK-21, KMK-22 and KMK-23 strains grown in $55 \mathrm{~g} \mathrm{~L}^{-1} \mathrm{glycerol}^{-1}$ medium. $\mathbf{c ~ N A D H / N A D}$ ratios and $\mathbf{d} \mathrm{NADH}$ and NAD ${ }^{+}$concentrations of KMK-23 grown in the medium containing $40 \mathrm{~g} \mathrm{~L}^{-1} \mathrm{glycerol} \mathrm{and} 20 \mathrm{~g} \mathrm{~L}^{-1}$ various co-substrates; mannitol (Man), glucose (Glc), xylose (Xyl) and galactose (Gal)

Table 4 Comparison of $\mathrm{OD}_{600}$, glycerol consumption, 1,3-PDO production and yield in KMK-12 and its mutants after $24 \mathrm{~h}$ of flask culture ${ }^{a}$

\begin{tabular}{lcccc}
\hline $\begin{array}{l}\text { dhaD } \\
\text { glpK }\end{array}$ & & $\Delta$ & $\Delta$ & $\Delta$ \\
\hline Strain name & KMK-12 & & KMK-22 & KMK-23 \\
\hline OD $_{600}$ & 3.53 & 3.26 & 3.32 & 3.85 \\
Consumed glycerol $\left(\mathrm{g} \mathrm{L}^{-1}\right)$ & 10.49 & 7.49 & 13.56 & 7.59 \\
Consumed glucose $\left(\mathrm{g} \mathrm{L}^{-1}\right)$ & 7.80 & 9.24 & 7.15 & 1.47 \\
Acetate production $\left(\mathrm{g} \mathrm{L}^{-1}\right)$ & 0 & 2.25 & 0.20 & 1.97 \\
Succinate production $\left(\mathrm{g} \mathrm{L}^{-1}\right)$ & 0.23 & 0.14 & 6.09 & 0.25 \\
1,3-PDO production $\left(\mathrm{g} \mathrm{L}^{-1}\right)$ & 4.87 & 4.79 & 0.25 & 5.27 \\
1,3-PDO productivity $\left(\mathrm{g} \mathrm{L}^{-1} \mathrm{~h}^{-1}\right)$ & 0.20 & 0.20 & 0.54 & 0.22 \\
1,3-PDO yield (mol $\left.\mathrm{mol}^{-1}\right)^{\mathrm{b}}$ & 0.56 & 0.77 & 0.84 \\
\hline
\end{tabular}

a Experiments were repeated three times independently

b Yield is calculated as dividing produced metabolite by consumed glycerol

was highest when mannitol was used as co-substrate (Fig. 2c, d). It is suspected that this additional NADH was beneficial to 1,3-PDO production, since 1,3-PDO production requires NADH for DhaT (NCBI-Protein ID: AEJ99987) enzymatic reaction (Fig. 2c, d).
However, when mannitol was used as a co-substrate, its consumption over $24 \mathrm{~h}$ was much higher than consumption of other co-substrates (Fig. 3). To reduce fermentation cost, mannitol consumption should be restricted. Here, we attempted to solve it by decreasing 
$\mathbf{a}$

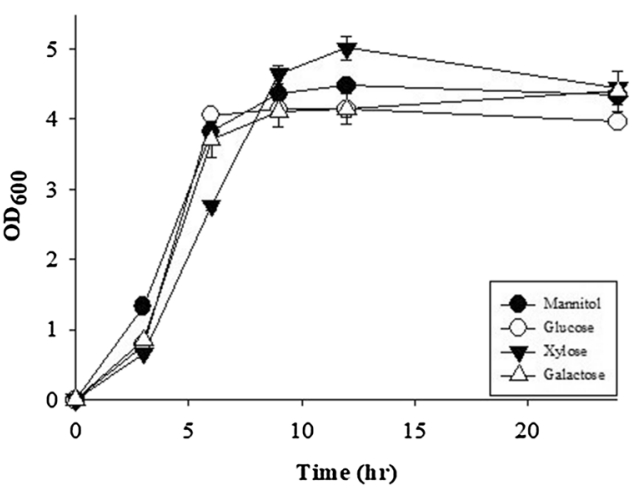

c

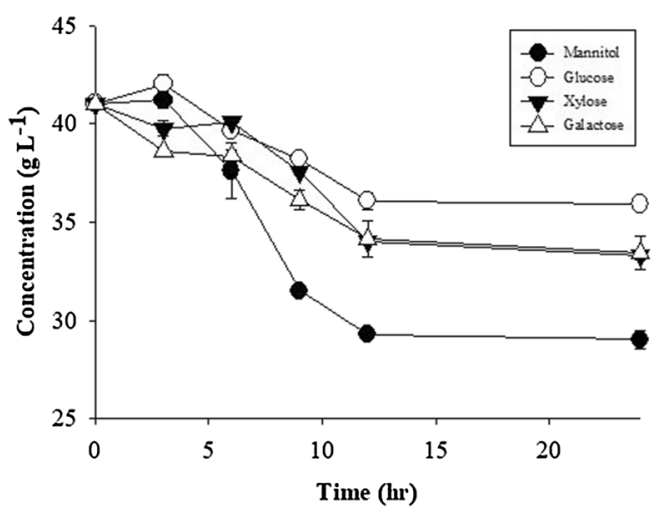

b

\section{Co-substrates}

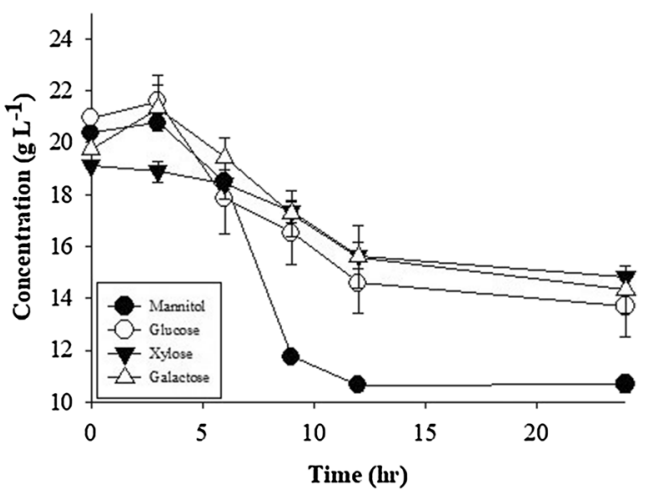

d 1,3-PDO

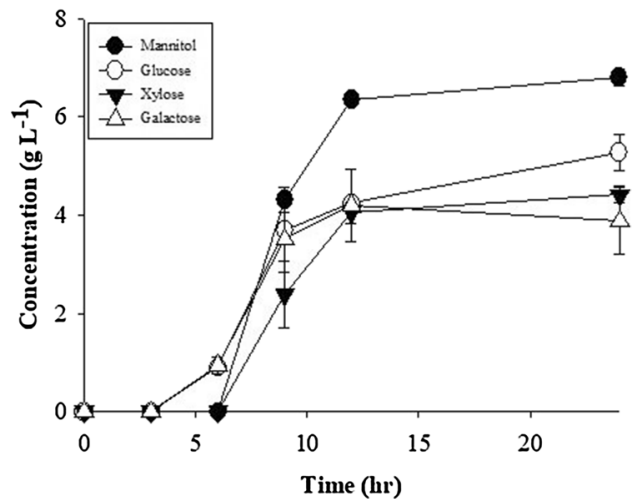

Fig. 3 a Microbial growth $\left(\mathrm{OD}_{600}\right)$, b consumption of co-substrates, $\mathbf{c}$ consumption of glycerol, and $\mathbf{d}$ 1,3-PDO production of KMK-23 in flask culture in the medium containing $40 \mathrm{~g} \mathrm{~L}^{-1}$ glycerol and $20 \mathrm{~g} \mathrm{~L}^{-1}$ four different co-substrates; mannitol (filled circle), glucose (empty circle), xylose (filled reversed triangle), and galactose (empty triangle)

the expression level of mannitol-specific transporter, MtlA (NCBI-Protein ID: AEK00431) by genome editing [32-34]. The 5'-UTR sequence of the $m t l A$ was determined by RBS calculator and then was edited by CRISPR/Cas9 method as described in "Methods". The resulting strain was confirmed by sequencing and designated as KMK-23M. The expression level of $m t l A$ in KMK-23M was decreased 25\% compared to KMK-23 (Additional file 5: Figure S2A). Mannitol consumption of KMK-23M until $24 \mathrm{~h}$ was reduced from 9.68 to $6.28 \mathrm{~g} \mathrm{~L}^{-1}$ compared to that of KMK-23, while cell mass and 1,3-PDO production both increased substantially by 31 and 34\%, respectively (Fig. 4). No reduction was observed in molar yield of 1,3-PDO from glycerol. This suggests that for KMK-23, the glycolytic flux supplied by mannitol exceeded the optimal point. Therefore, reducing glycolytic flux in KMK-23M benefited both cell growth and the conversion of glycerol to 1,3-PDO.

\section{Engineering of transcriptional regulation of the dha operon}

Figure $1 \mathrm{~b}$ presents the arrangement of the dha genes in the $K$. pneumoniae genome. The genes encoding the enzymes are directly involved in 1,3-PDO production, 


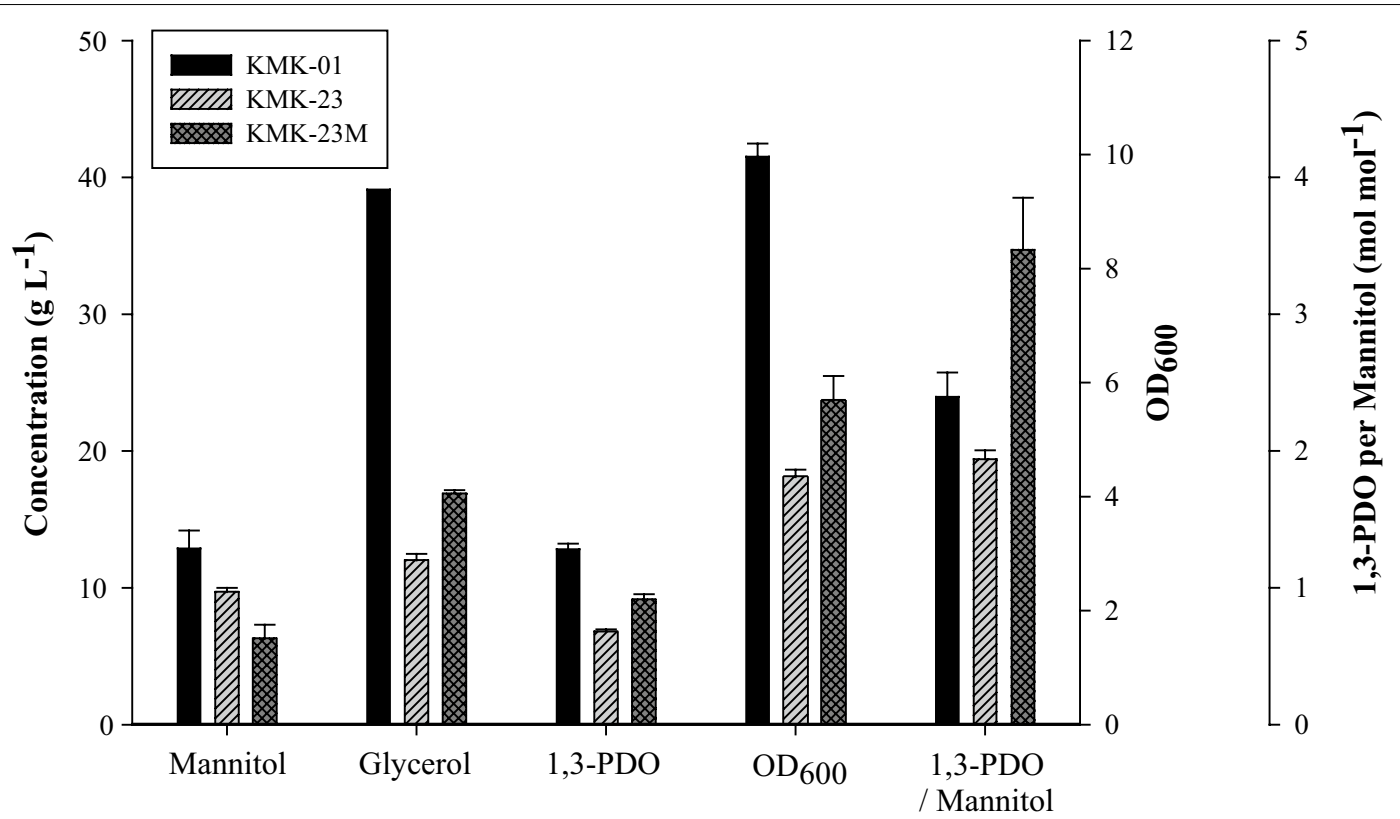

Fig. 4 Effects of genome editing on 5'-UTR of mt/A gene for its reduced expression on carbon source consumption and metabolite productions. When three strains, KMK-01 (wild type, black bar), KMK-23 (dashed bar), and KIK-23M (genome-edited strain, gray bar), were cultured in the medium containing $40 \mathrm{~g} \mathrm{~L}^{-1}$ glycerol and $20 \mathrm{~g} \mathrm{~L}^{-1}$ mannitol, mannitol and glycerol consumption, 1,3-PDO production, microbial growth $\left(\mathrm{OD}_{600}\right)$, and 1,3-PDO production per unit mannitol consumption for $24 \mathrm{~h}$ were compared

dhaB (Gene ID: 12547480 [Genbank]) and dhaT (Gene ID: 12547484 [Genbank]), which belong to the dha operon [14]. According to a study by Bächler et al. [35], the promoter of the dhaKLM operon in Escherichia coli, PdhaK, is negatively regulated by DhaK and DhaM, and positively regulated by DhaL. Dephosphorylated DhaL can bind the sensing domain of DhaR (NCBI-Protein ID: AEJ99990) and activate DhaR. DhaR positively regulates dhaT expression, but negatively regulates $d$ ha $B$ [36]. Negative regulation of $d h a B$ could be beneficial to 1,3-PDO production because the product of DhaB, 3-hydroxypropionaldehyde, is a toxic intermediate [37]. DhaR is repressed by DhaK, while activated by dephosphorylated DhaL that is inactivated by DhaM-mediated phosphorylation [35, 38]. In other words, dhaK and dhaM negatively regulate and dhaL positively regulates dhaT expression via DhaR.

We deleted dhaKLM on KMK-23M strain genome and named the resulting strain KMK-46. Then, the dhaL gene-encoding activator was overexpressed and the resulting strain was designated KMY, expecting DhaR activated by DhaL transcriptionally upregulates dhaT expression (Fig. 1b). To demonstrate the expression level changes of dhaR, dhaL and dhaT quantitative RTPCR was conducted in KMK-23M, KMK-46, and KMY strains. The expression levels of dhaR were not changed significantly in those engineered strain (Fig. 5a). On the other hand, dhaL expression levels confirmed that dhaKLM deletion and dhaL overexpression were properly conducted in KMK-46 and KMY strains (Fig. 5b). As expected, dhaT expression in KMY was increased threefold than KMK-23M and KMK-46 (Fig. 5c). Interestingly, KMK-46, dhaKLM deleted strain, did not produce 1,3-PDO at all, while dhaL overexpression in that strain increased 1,3-PDO production by $26.4 \%$ compared to KMK-23M (Fig. 6a-d). The molar yield of KMY was also $20 \%$ higher than for KMK-23M (Fig. 6e). This is contrast to the result of overexpression of dhaR (Additional file 5: Figure S2B) in the KMK-46 strain, resulted in no 1,3-PDO production (data not shown). In addition, 

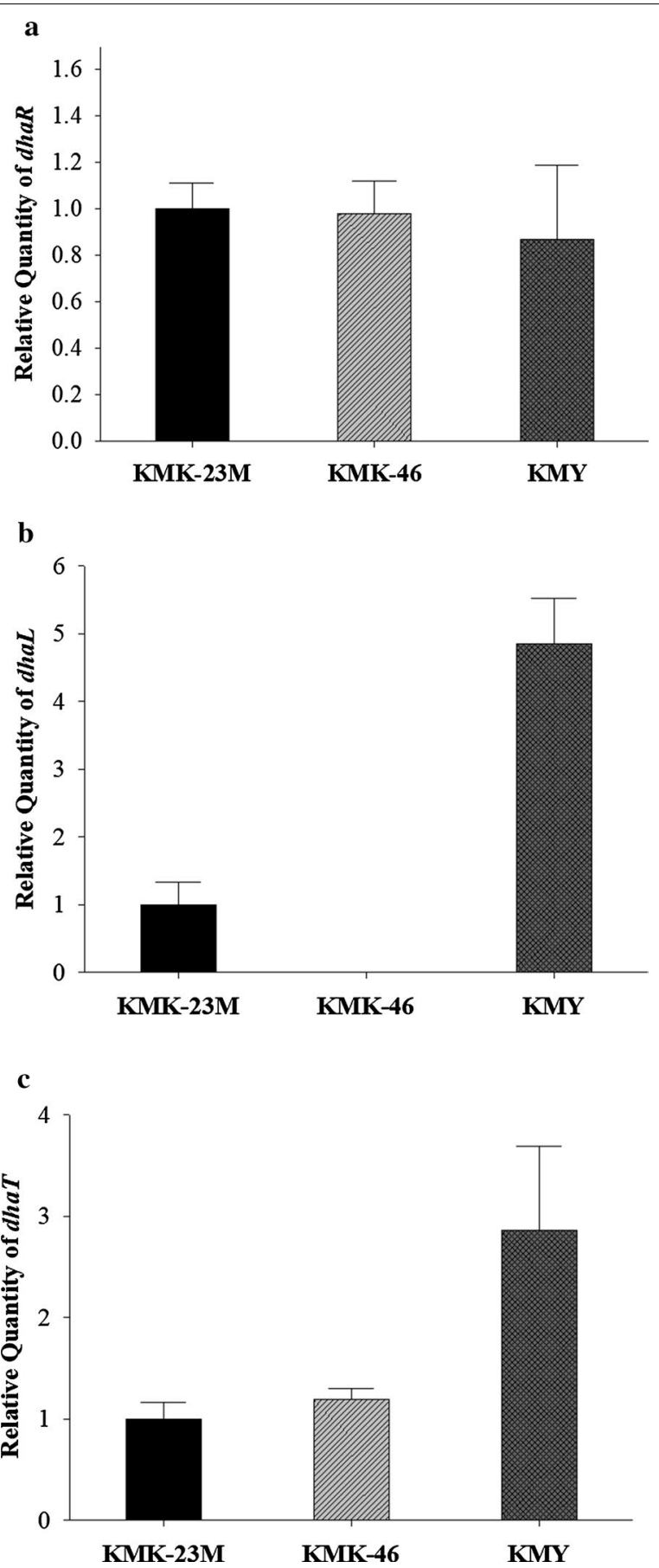

Fig. 5 Relative expression levels of $\mathbf{a} d h a R, \mathbf{b}$ dhaL and $\mathbf{c}$ dhaT in KMK-23M, KMK-46 and KMY strains detected by real-time RT-PCR. The expression levels of KMK-46 and KMY were normalized with cell mass $\left(\mathrm{OD}_{600}\right)$ and with the ones of control strain, KMK-23M. The expression levels were measured three times with the strains grown in $40 \mathrm{~g} \mathrm{~L}^{-1}$ glycerol and $20 \mathrm{~g} \mathrm{~L}^{-1}$ mannitol up to mid-log phase and the error bars represented the standard deviations when dhaT was overexpressed in KMK-23M and KMK46 strains, 1,3-PDO production was much less than that of KMY (data not shown). These results suggest that the regulation of $d h a$ operon is not simple and has not been fully understood yet. In this study, the developed KMY strain with deletion of $d h a K L M$ and overexpression of dhaL partially proved their regulatory functions on dhaT expression.

Batch fermentation was performed with the resulting strain, KMY. A total of $20.59 \mathrm{~g} \mathrm{~L}^{-1} 1,3$-PDO was produced in $24 \mathrm{~h}$ with a molar yield of $0.76 \mathrm{~mol} \mathrm{~mol}^{-1}$ glycerol (Fig. 6f). The 1,3-PDO yield from the carbon sources in total, including mannitol, was $0.54 \mathrm{~g} \mathrm{~g}^{-1}$. The molar yield in this study was superior to that reported in other published studies; these studies reported molar yields of around $0.6 \mathrm{~mol} \mathrm{~mol}^{-1}$ glycerol $[15,16]$. The increase in the 1,3-PDO titer from batch fermentation compared to culturing in flasks may be due to the $\mathrm{pH}$ control during the process. During the entire fermentation, dissolved oxygen level was maintained at near zero percent, because the microaerobic condition with low aeration has been known to be beneficial for 1,3PDO production [5]. The developed strain produced significantly lower amounts of byproducts with a much higher molar yield of 1,3-PDO from glycerol. This could be extremely helpful in reducing the cost of product separation [11]. The high-molar yield of 1,3-PDO was enabled by eliminating genes in the glycerol assimilation pathway and feeding bacteria a co-substrate for cell mass and maintenance energy. Regulators influencing expression of $d h a T$ were also helpful in increasing 1,3-PDO production and yield compared to the parental strain. With continuous metabolic engineering, a cost-effective biochemical process to produce 1,3-PDO using K. pneumoniae would be possible near future.

\section{Conclusions}

In this study, we minimized the production of byproducts during 1,3-PDO synthesis by deleting the pathway genes from the K. pneumoniae genome. Next, the glycerol assimilation pathway was eliminated and mannitol was fed as a co-substrate to improve glycerol flux towards 1,3-PDO production. The $5^{\prime}$-UTR of $m t l A$ was edited to reduce mannitol consumption. Finally, 1,3-PDO production was enhanced by modifying dha regulation through deletion of dhaKLM and overexpression of dhaL. In 
a

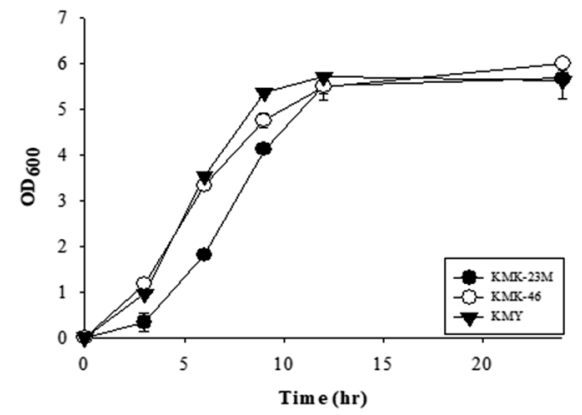

c

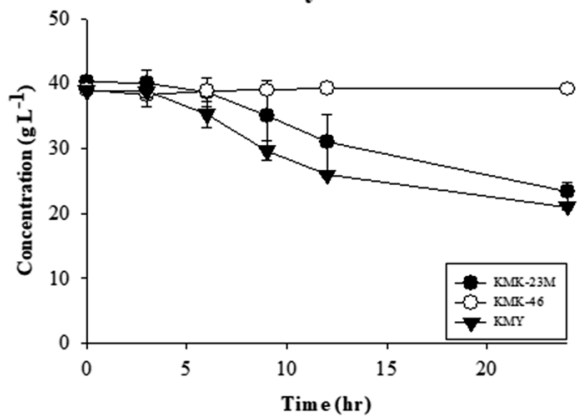

$\mathbf{e}$

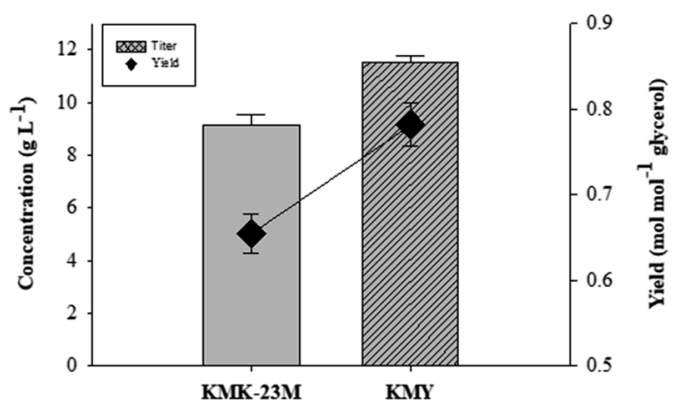

b

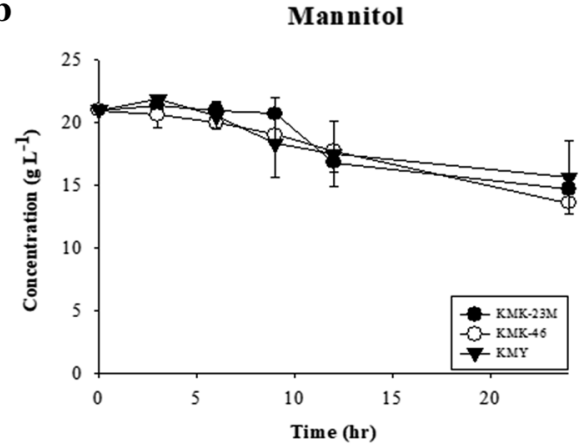

d

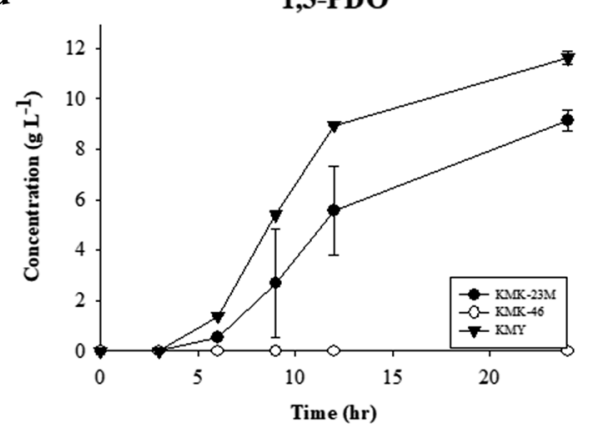

f

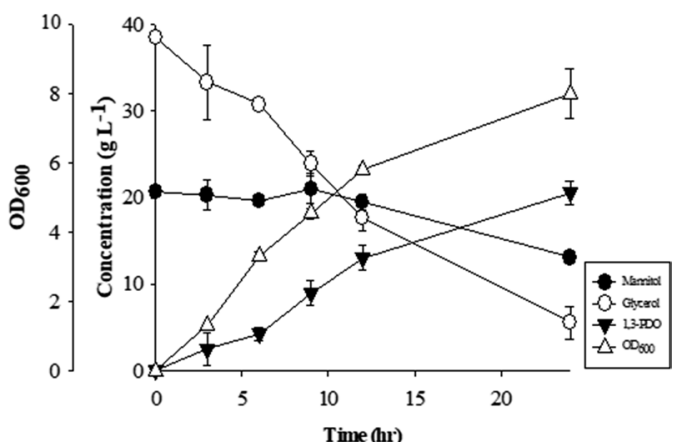

Fig. 6 a Microbial growth $\left(\mathrm{OD}_{600}\right)$, b mannitol, c glycerol, and d 1,3-PDO concentrations of KMK-23M (filled circle), KMK-46 (empty circle), and KMY (filled reversed triangle) strains in flask culture. e Comparison of 1,3-PDO production $\left(\mathrm{g} \mathrm{L}^{-1}\right)$ and its molar yield (mol mol ${ }^{-1} \mathrm{glycerol}$ ) between KMK-23M and KMY strains during $24 \mathrm{~h}$. Bars represent titer and diamond-shaped dot represent yields. $\mathbf{f}$ Batch fermentation results of KMY strain with the concentrations of mannitol (filled circle) and glycerol (empty circle), 1,3-PDO (filled reversed triangle), and OD 600 (empty triangle)

batch fermentation, 1,3-PDO was produced with the yield of $0.76 \mathrm{~mol} \mathrm{~mol}^{-1}$ glycerol. The molar yield in this study was superior to previously published studies.

\section{Additional file}

Additional file 1. Table S1: Oligonucleotides used in this study.

Additional file 2. Figure S1: Confirmation experiments for deletion mutants. A PCR fragments from genomic DNA of K. pneumoniae KCTC 2242, KMK-01, KMK-02 and KMK-05 for wabG, IdhA, pfB, budA sites. B PCR fragments from KMK-12, KMK-21, KMK-22 and KMK-23 for dhaD and glpK sties. C PCR fragments from KMK-23M and KMK-46 for dhaKLM site. The genes from control strains are written in red, while ones from deleted strains are written in light blue.

Additional file 3. Table S2: Fermentation data of KMK-12 and its mutants after 24 hrs of flask cultivation with $40 \mathrm{~g} \mathrm{~L}^{-1}$ glycerol as a sole carbon source.

Additional file 4. Table S3: Fermenation data of KMK-12 and its mutants after 24 hrs of flask cultivation with $40 \mathrm{~g} \mathrm{~L}^{-1}$ glucose as a sole carbon source.

Additional file 5. Figure S2: Relatively gene expression levels of $\mathbf{A} m t / A$ in KMK-23 and KMK-23M when glucose or mannitol was used as a cosubstrate and $\mathbf{B}$ dhaR when the gene was overexpressed in KMK46 strain. The gene expression levels were detected by quantitative RT-PCR. 


\section{Abbreviations}

1,3-PDO: 1,3-propanediol; 2,3-BDO: 2,3-butanediol; BudA: alpha-acetonelactate decarboxylase; DhaB: glycerol dehydratase; DhaD: glycerol dehydrogenase; DhaK: dihydroxyacetone kinase subunit K; DhaL: dihydroxyacetone kinase subunit L; DhaM: dihydroxyacetone kinase subunit M; DhaR: DNA-binding transcriptional regulator of dha operon; DhaT: 1,3-PDO dehydrogenase; GlpK: glycerol kinase; LdhA: lactate dehydrogenase; MtlA: mannitol-specific transporter; PdhaK: dhaK promoter; PflB: formate acetyltransferase.

\section{Authors' contributions}

The study was designed by MKO and MYJ. JHL and MYJ performed the experiments and analyzed the results together with MKO. The manuscript was drafted by JHL with contributions from all authors. All authors read and approved the final manuscript.

\section{Author details}

1 Department of Chemical and Biological Engineering, Korea University, Seongbuk-gu, Seoul 02841, Republic of Korea. ${ }^{2}$ CJ Research Institute of Biotechnology, Suwon, Gyeonggi 16495, Republic of Korea.

\section{Acknowledgements}

Not applicable.

\section{Competing interests}

The authors declare that they have no competing interests.

\section{Availability of data and materials}

The datasets used and/or analyzed during the current study are available from the corresponding author on reasonable requests.

\section{Consent for publication}

Not applicable.

\section{Ethics approval and consent to participate} Not applicable.

\section{Funding}

This study was supported by a grant from the New \& Renewable Energy Program of the Korea Institute of Energy Technology Evaluation and Planning (No. 20143030091040); and a grant from the National Research Foundation of Korea funded by the Korean Government (2012M1A2A2026560 and 2015M3D3A1A01064919).

\section{Publisher's Note}

Springer Nature remains neutral with regard to jurisdictional claims in published maps and institutional affiliations.

\section{Received: 27 December 2017 Accepted: 30 March 2018} Published online: 09 April 2018

\section{References}

1. Yang F, Hanna MA, Sun R. Value-added uses for crude glycerol-a byproduct of biodiesel production. Biotechnol Biofuels. 2012;5:3.

2. da Silva GP, Mack M, Contiero J. Glycerol: a promising and abundant carbon source for industrial microbiology. Biotechnol Adv. 2009;27:20-39.

3. Lee CS, Aroua MK, Daud WAW, Cognet P, Peres-Lucchese Y, Fabre PL, Reynes $O$, Latapie L. A review: conversion of bioglycerol into 1,3-propanediol via biological and chemical method. Renew Sustain Energy Rev. 2015;42:963-72

4. Anand P, Saxena RK, Marwah RG. A novel downstream process for 1,3-propanediol from glycerol-based fermentation. Appl Microbiol Biotechnol. 2011;90:1267-76.

5. Saxena RK, Pinki A, Saurabh S, Jasmine I. Microbial production of 1,3-propanediol: recent developments and emerging opportunities. Biotechnol Adv. 2009;27:895-913.

6. Kumar V, Park S. Potential and limitations of Klebsiella pneumoniae as a microbial cell factory utilizing glycerol as the carbon source. Biotechnol Adv. 2017:36:150-67.
7. Wang M, Wang G, Zhang T, Fan L, Tan T. Multi-modular engineering of 1,3-propanediol biosynthesis system in Klebsiella pneumoniae from cosubstrate. Appl Microbiol Biotechnol. 2017:101:647-57.

8. Xin B, Tao F, Wang Y, Liu H, Ma C, Xu P. Coordination of metabolic pathways: enhanced carbon conservation in 1,3-propanediol produc tion by coupling with optically pure lactate biosynthesis. Metab Eng. 2017:41:102-14.

9. Kumar V, Durgapal M, Sankaranarayanan M, Somasundar A, Rathnasigh C, Song $\mathrm{H}$, Seung D, Park S. Effects of mutation of 2,3-butanediol formation pathway on glycerol metabolism and 1,3-propanediol production by Klebsiella pneumoniae J2B. Bioresour Technol. 2016;214:432-40.

10. Lin J, Zhang Y, Xu D, Xiang G, Jia Z, Fu S, Gong H. Deletion of poxB, pta, and ackA improves 1,3-propanediol production by Klebsiella pneumoniae. Appl Microbiol Biotechnol. 2016;100:2775-84.

11. Xiu ZL, Zeng AP. Present state and perspective of downstream processing of biologically produced 1,3-propanediol and 2,3-butanediol. Appl Microbiol Biotechnol. 2008;78:917-26.

12. Jung MY, Mazumdar S, Shin HS, Yang KS, Lee J, Oh MK. Improvement of 2,3-butanediol yield in Klebsiella pneumonia by deletion of the pyruvate formate-lyase gene. Appl Environ Microbiol. 2014:80:6195-203.

13. Zhang G, Yang G, Wang X, Guo Q, Li J. Influence of blocking of 2,3-butanediol pathway on glycerol metabolism for 1,3-propanediol production by Klebsiella oxytoca. Appl Biochem Biotechnol. 2012;168:116-28.

14. Sun J, Heuvel J, Soucaille P, Qu Y, Zeng A. Comparative genomic analysis of tha regulon and related genes for anaerobic glycerol metabolism in bacteria. Biotechnol Prog. 2003;19:263-72.

15. Huang J, Wu Y, Wu W, Liu D, Chen Z. Cofactor recycling for co-production of 1,3-propanediol and glutamate by metabolically engineered Corynebacterium glutamicum. Sci Rep. 2017;7:42246.

16. Kaur G, Srivastava AK, Chand S. Advances in biotechnological production of 1,3-propanediol. Biochem Eng J. 2012;64:106-18.

17. Shin SH, Kim S, Kim JY, Lee S, Um Y, Oh MK, Kim YR, Lee J, Yang KS. Complete genome sequence of the 2,3-butanediol-producing Klebsiella pneumoniae strain KCTC 2242. J Bacteriol. 2012;194:2736-7.

18. Datsenko KA, Wanner BL. One-step inactivation of chromosomal genes in Escherichia coli K-12 using PCR products. Proc Natl Acad Sci USA. 2000;97:6640-5.

19. Borujeni AE, Channarasappa AS, Salis HM. Translation rate is controlled by coupled trade-offs between site accessibility, selective RNA unfolding and sliding at upstream standby sites. Nucleic Acids Res. 2013:42:2646-59.

20. Salis HM, Mirsky EA, Voigt CA. Automated design of synthetic ribosome binding sites to control protein expression. Nat Biotechnol. 2009;27:946-52

21. Jiang WY, Bikard D, Cox D, Zhang F, Marraffini LA. RNA-guided editing of bacterial genomes using CRISPR-Cas systems. Nat Biotechnol. 2013;31:233-9.

22. Qi LS, Larson MH, Gilbert L, Doudna JA, Weissman JS, Arkin AP, Lim WA. Repurposing CRISPR as an RNA-guided platform for sequence-specific control of gene expression. Cell. 2013;152:1173-83.

23. Heo MJ, Jung HM, Um J, Lee SW, Oh MK. Controlling citrate synthase expression by CRISPR/Cas9 genome editing for $n$-butanol production in Escherichia coli. ACS Synth Biol. 2017:6:182-9.

24. Gibson DG, Glass JI, Lartique C, Noskov VN, Chuang RY, Algire MA, Benders GA, Montague MG, Ma L, Moodie MM, Merryman C, Bashee S, Krishnakumar R, Assad-Garcia N, Andrews-Pfannkoch C, Denisova EA, Young L, Qi ZQ, Seqall-Shapiro TH, Calvey CH, Hutchison CA 3rd, Smith HO, Venter JC. Creation of a bacterial cell controlled by a chemically synthesized genome. Science. 2010;329:52-6.

25. Gibson DG, Young L, Chuang RY, Venter JC, Hutchison CA 3rd, Smith HO. Enzymatic assembly of DNA molecules up to several hundred kilobases. Nat Methods. 2009:6:343-5.

26. Izquierdo L, Coderch N, Pique N, Bedini E, Corsaro MM, Frensno S, Tomas JM, Reque M. The Klebsiella pneumoniae wabG gene: role in biosynthesis of the core lipopolysaccharide and virulence. J Bacteriol. 2003:185:7213-21.

27. Celińska E. Debottlenecking the 1,3-propanediol pathway by metabolic engineering. Biotechnol Adv. 2010;28:519-30.

28. Johnson EA, Lin EC. Klebsiella pneumoniae 1,3-propanediol: $\mathrm{NAD}^{+}$oxidoreductase. J Bacteriol. 1987;169:2050-4 
29. Forage RG, Lin EC. DHA system mediating aerobic and anaerobic dissimilation of glycerol in Klebsiella pneumoniae NCIB 418. J Bacteriol. 1982;151:591-9.

30. Ashok S, Raj SM, Ko Y, Sankaranarayanan M, Zhou S, Kumar V, Park S. Effect of puuC overexpression and nitrate addition on glycerol metabolism and anaerobic 3-hydroxypropionic acid production in recombinant Klebsiella pneumoniae $\Delta g$ lpK $\Delta$ dhaT. Metab Eng. 2013;15:10-24.

31. De Mey M, De Maeseneire S, Soetaert W, Vandamme E. Minimizing acetate formation in E. coli fermentations. J Ind Microbiol Biotechnol. 2007;34:689-700.

32. Otte $\mathrm{S}$, Lengeler JW. The $\mathrm{mtl}$ genes and the mannitol-1-phosphate dehydrogenase from Klebsiella pneumoniae KAY2026. FEMS Microbiol Lett. 2001;194:221-7.

33. Honeyman AL, Curtiss R 3rd. The mannitol-specific enzyme II ( $m$ t/A) gene and the $m t / R$ gene of the PTS of Streptococcus mutants. Microbiology. 2000;146:1565-72.
34. Rudd KE. EcoGene: a genome sequence database for Escherichia coli K-12. Nucleic Acids Res. 2000;28:60-4.

35. Bächler C, Schneider P, Bächler P, Lustig A, Erni B. Escherichia coli dihydroxyacetone kinase controls gene expression by binding to transcription factor DhaR. EMBO J. 2005;24:283-93.

36. Zheng P, Wereath K, Sun J, Van den Heuvel J, Zeng AP. Overexpression of genes of the dha regulon and its effects on cell growth, glycerol fermentation to 1,3-propanediol and plasmid stability in Klebsiella pneumoniae. Process Biochem. 2006;41:2160-9.

37. Barbirato F, Grivet JP, Soucaille P, Bories A. 3-Hydroxypropionaldehyde, an inhibitory metabolite of glycerol fermentation to 1,3-propanediol by enterobacterial species. Appl Environ Microbiol. 1996;62:1448-51.

38. Deutscher J, Francke C, Postma PW. How phosphotransferase systemrelated protein phosphorylation regulates carbohydrate metabolism in bacteria. Microbiol Mol Biol Rev. 2006;70:939-1031.

\section{Submit your next manuscript to BioMed Central and we will help you at every step:}

- We accept pre-submission inquiries

- Our selector tool helps you to find the most relevant journal

- We provide round the clock customer support

- Convenient online submission

- Thorough peer review

- Inclusion in PubMed and all major indexing services

- Maximum visibility for your research

Submit your manuscript at www.biomedcentral.com/submit 